\title{
Epidemiology of paracoccidioidomycosis in Venezuela: a retrospective study from 1954 to 2019
}

\section{Primavera Alvarado ${ }^{1,2} /{ }^{+}$, Marcus de Melo Teixeira ${ }^{3}$, Elsy Cavallera1, Hugo Costa Paes ${ }^{3}$, Giovanni Guerra', Gerardo Santander ${ }^{4}$, Rommie Merino-Alado ${ }^{5}$}

\author{
${ }^{1}$ Instituto Autónomo de Biomedicina Dr Jacinto Convit, Laboratorio de Micología, Caracas, Miranda, Venezuela \\ ${ }^{2}$ Universidad Central de Venezuela, Facultad de Medicina, Caracas, Miranda, Venezuela \\ ${ }^{3}$ Universidade de Brasília, Faculdade de Medicina, Brasília, DF, Brasil \\ ${ }^{4}$ Universidad Central de Venezuela, Instituto de Geografía Regional, Caracas, Miranda, Venezuela \\ ${ }^{5}$ Universidad Central de Venezuela, Facultad de Odontología, Caracas, Miranda, Venezuela
}

BACKGROUND Paracoccidioidomycosis (PCM) is a systemic mycosis endemic to Latin America. Etiological agents are Paracoccidioides species that diverge phylogenetically throughout South America.

OBJECTIVES This study aimed to document the epidemiology of PCM in Venezuela.

METHODS We have performed a retrospective cross-sectional descriptive study in 31,081 clinical records of patients from two reference centres during 65 years (1954-2019).

FINDINGS PCM diagnosis was confirmed in 745 patients. Chronic PCM was the most prevalent form (90.06\% cases); $80.67 \%$ were male and the most affected age range was 41-60. Farming and construction were the most prevalent occupation and Miranda State had a higher prevalence. Lung and skin were the most affected organs, followed by oral manifestations. Direct examination, culture and serology showed a high sensibility, and no statistical difference was observed among the diagnostic tools. Out of 17 Paracoccidioides isolates genotyped from Venezuela, one was typed as Paracoccidioides americana and 16 as Paracoccidioides venezuelensis.

MAIN CONCLUSIONS Clinical manifestations observed, information about the epidemiology and molecular profile is essential not only for diagnosis but also for understanding therapeutic responses to mycotic drugs and prognosis. Therefore, it is necessary to sequence all positive isolated strains in order to confirm the dominance of $P$. venezuelensis in Venezuela.

Key words: paracoccidioidomycosis - epidemiology - diagnosis - Paracoccidioides venezuelensis

Paracoccidioidomycosis (PCM) is a systemic granulomatous disease restricted to Latin America and mostly reported in humid and tropical areas of Brazil, Colombia, Venezuela, and Argentina. (1) This mycosis is highly prevalent in rural areas, affecting patients with low socioeconomic status and leading to life-threatening clinical conditions. However, cases have been reported in urban areas linked to constructions, recent urbanisation, and patients with underlying immunosuppression. $(2,3)$ The etiological agents of PCM belong to the genus Paracoccidioides in the family Ajellomycetaceae, order Onygenales, along with other endemic human pathogens such as Histoplasma spp. and Coccidioides spp. ${ }^{(4)}$ Paracoccidioides spp. are thermally dimorphic fungi that exhibit two morphotypes: a mold occurring at temperatures below $28^{\circ} \mathrm{C}$, composed of thin septate hyphae that might produce conidia (considered as the infectious propagules); ${ }^{(5)}$ and a yeast form found in cultures or in the host at $37^{\circ} \mathrm{C}$ and composed of variably-sised multibudding oval to round cells. ${ }^{(6)}$

doi: 10.1590/0074-02760210203

+ Corresponding author: prima558@gmail.com

(D) https://orcid.org/0000-0002-5965-6827

Received 09 June 2021

Accepted 21 September 2021
In recent years, the taxonomy of the genus has changed; before 2006, Paracoccidioides only included one species, Paracoccidioides brasiliensis. ${ }^{(4)}$ In 2009, Teixeira et al. reported the phylogenetic distribution of Paracoccidioides in a wide range of isolates using multilocus DNA sequence typing. The authors described a new species named Paracoccidioides lutzii that is endemic to Midwestern Brazil, with few cases observed in the Southeast and Ecuador. ${ }^{(7,8,9)}$ However, the finding of cryptic species within P. brasiliensis drove researchers to explore the evolutionary mechanisms that were responsible for the geographic distribution of four other molecular clades that had been previously characterised in it (S1, PS2, PS3, PS4). Recently, Turissini et al. ${ }^{(10)}$ performed a study on 65 isolates of $P$. brasiliensis to compare nuclear and mitochondrial DNA polymorphisms and in vitro phenotypic variation in isolate morphology. These data led to the establishment of a new classification of the $P$. brasiliensis complex comprised of four new species: $P$. brasiliensis sensu stricto (clades S1a and S1b), Paracoccidioides americana (PS2), Paracoccidioides restrepiensis (PS3) and Paracoccidioides venezuelensis (PS4). ${ }^{(10)} P$. brasiliensis sensu stricto is widely dispersed in the southern part of South America. P. americana (PS2) has been reported in southeast Brazil and rarely in Venezuela, $P$. restrepiensis (PS3) is found predominantly in Colombia and in other Latin American countries and $P$. venezuelensis (PS4) appears to be dominant in Venezuela. ${ }^{(11)}$ 
PCM is a pleomorphic disease with diverse clinical manifestations that can lead to misdiagnosis. In 1986, during the Coloquio Internacional en Paracoccidioidomicosis (Medellín, Colombia), the disease classification still in use was proposed: acute/subacute, chronic, and residual. ${ }^{(12)}$ Chronic PCM is the most prevalent clinical form of the disease (up to $74 \%-96 \%$ of the reports), characterised by pulmonary and oral lesions due to lymphohematogenous dissemination of the pathogen. Most patients are male and lesions are usually deep and painful granulomatous-like lesions; pulmonary insufficiency can be reported in these cases. Lesions can be found in the mouth, intestines, adrenal glands, central nervous system, lymph nodes and bones. In contrast, the acute/sub-acute form is frequently observed in infants and adolescents, representing $5 \%$ to $25 \%$ of reported cases and featuring hepatosplenomegaly and severe lymphadenopathy. ${ }^{(13,14)}$

In Venezuela, the first cases of PCM were reported by O'Daly (1937) ${ }^{(15)}$ and Guerra (1948), who addressed the importance of studying the lung manifestations of the illness. ${ }^{(16)}$ In 1971, Albornoz performed the first isolation of the fungus from soil samples collected at the Miranda State ${ }^{(17)}$ and coupled with some evidence of high positivity of intradermic surveys in the area. In the past 30 years, Venezuela has gained prominence in the PCM epidemiological roadmap due to the high incidence in the North part of the country as well as in the Bolivar State, which is characterised by tropical rainforest. ${ }^{(18)}$ This places Venezuela third in the numbers of reported cases of this deep mycosis, in association with a unique Paracoccidioides species. Therefore, this study aimed to characterise the clinical and epidemiological aspects of the PCM caused by Paracoccidioides species in Venezuela.

\section{MATERIALS AND METHODS}

Study design - We conducted a retrospective, crosssectional and descriptive study by evaluating patients' medical records referred to the Dermatology Department of the Hospital Vargas, Instituto Autónomo de Biomedicina "Dr. Jacinto Convit", Laboratorio de Micología. Caracas, Venezuela and Microbiology Department of the Dentistry School, Universidad Central de Venezuela (UCV). We reviewed 31,081 clinical records of patients in a 65-year period (from 1954 to 2019). Data from Dentistry School were available from 2016-2019. All centres received patients and samples from the Metropolitan area and from outside the capital region.

Data collection - Data collected included demographic, epidemiological, clinical and radiographic findings of the PCM cases observed in patients who attend the medical centers as mentioned above.

Ethical statements - Patients' data were included after ethical consent using an anonymous instrument previously approved by the Ethics Committee Board of the Instituto Autónomo de Biomedicina "Dr. Jacinto Convit" (number 08/08/2016).

Laboratory diagnosis - PCM diagnoses were confirmed by either direct examination, microbiological isolation or serological tests. Direct examinations were performed from biopsies and stained with $40 \% \mathrm{KOH}$ and Giemsa stain. For the microbial isolation of Paracoccidioides sp., the affected tissues were cultured in Sabouraud Dextrose Agar (SDA), with chloramphenicol, and incubated at $25^{\circ} \mathrm{C}$ and $37^{\circ} \mathrm{C}$ for 60 days. Macro - and microscopic characteristics compatible with Paracoccidioides $\mathrm{sp}$. were searched. Later, all positive cultures were stored in distilled water according to the Castellani method and recovered for additional analysis after new subcultures on SDA with chloramphenicol. ${ }^{(19)}$ After 1975, a double immunodiffusion assay (serology) was implemented as part of the diagnosis algorithm in our centre. The Double immunodiffusion assay (DID) was performed for specific antibody detection, using $P$. brasiliensis antigen obtained from the $\mathrm{Pb} 339$ strain. ${ }^{(20)}$ All patients' sera were collected before PCM treatment and then in repeated drawings for the disease monitoring during a 6 -month period. In addition, serum titration was performed in all samples through serial dilutions in the course of diagnosis and treatment.

Molecular epidemiology - We evaluated 17 Venezuelan Paracoccidioides sp. strains genotyped so far using different research approaches by either restriction fragment length polymorphism (RFLP), rapid amplified DNA polymorphisms (RAPD), multi locus sequencing typing (MLST), or by whole genome typing (WST). In addition, the genotype and approximate location (to state level) were retrieved from previous studies. ${ }^{(4,11,21)}$

Statistical analysis - The patients' epidemiological and clinical data were represented as frequencies and their respective $95 \%$ confidence intervals were calculated. The Fisher exact test was also performed to analyse contingency tables by comparing clinical forms and affected organs.

The diagnostic tests were compared using $N-1$ Pearson's Chi-Square test with $95 \%$ confidence intervals $(95 \% \mathrm{CI})$. In addition, squared chi person $N-1$ was applied to determine statistical differences between groups. A $p$ value below 0.05 was considered statistically significant. (22) The classical quantitative variables, sensitivity and specificity, were determined with indicators oscillating between 0 and $100 \%$. The Pearson chi-squared test was employed to establish whether statistically significant differences existed between these variables. ${ }^{(23)}$

\section{RESULTS}

We retrospectively reviewed 31,081 medical records from 1954 to 2019; 745 (2.39\%) patients had PCM diagnosis confirmed by either direct examination, microbiological isolation, or serology. 601/745 (80.67\%) were males and 144/745 were females (19.32\%), a 4:1 maleto-female proportion. The age range was from 7 to 88 years and the mean age of affected individuals was 49.5 years (Table I). Regarding occupation, 242 (32.48\%) were rural workers, followed by other professions such as construction workers, general maintenance workers $(32.34 \%)$, builders $(12.34 \%)$, domestic service workers $(9.12 \%)$, among others (Table II). The distribution of diagnosed cases showed that most were in the 1975-1984 period, representing $52.01 \%$ of all diagnoses (Fig. 1). 
TABLE I

Age range by gender of patients with paracoccidioidomycosis (PCM) in Venezuela from 1954 to 2019

\begin{tabular}{lcccc}
\hline Age range (years) & Female & Male & Total & Ratio \\
\hline$<10$ & - & 11 & 11 & - \\
\hline $11-20$ & - & 17 & 17 & - \\
\hline $21-30$ & 2 & 37 & 39 & 18.5 \\
\hline $31-40$ & 7 & 69 & 76 & 9.9 \\
\hline $41-50$ & 25 & 221 & 246 & 8.8 \\
\hline $51-60$ & 77 & 152 & 229 & 2 \\
\hline $61-70$ & 24 & 64 & 88 & 2.6 \\
\hline$>70$ & 9 & 30 & 39 & 3.3 \\
\hline Total & 144 & 601 & 745 & 4.17 \\
\hline
\end{tabular}

TABLE II

Demography and epidemiological of patients with paracoccidioidomycosis (PCM) in Venezuela from 1954 to 2019

\begin{tabular}{lcc}
\hline Variables & $\mathrm{N}$ & Percentage (\%) \\
\hline Gender & & \\
\hline Male & 601 & 80.67 \\
Female & 144 & 19.32 \\
\hline Total & 745 & 100 \\
\hline Occupation & & \\
\hline Farmer & 242 & 32.48 \\
\hline General service worker & 241 & 32.34 \\
\hline Builder & 92 & 12.34 \\
\hline Housekeeping & 68 & 9.12 \\
\hline Merchant & 47 & 6.30 \\
\hline Student & 30 & 4.02 \\
\hline Ground transportation & 12 & 1.61 \\
\hline Electric technicians & 9 & 1.20 \\
\hline Engineers & 2 & 0.26 \\
\hline Teacher & 2 & 0.26 \\
\hline Total & 745 & 100 \\
\hline
\end{tabular}

We observed patients with PCM from all over the country, but most came from Miranda (75.03\%), Distrito Capital (12.61\%) and Aragua (3.08\%), located in the northeastern portion of the country (Fig. 2). Miranda State cases were overrepresented in a 10:3 ratio to all the other states, which is far more than its historical proportion of the population; Miranda State is located in the northern portion of the country and most of the cases were reported in rural areas compared to urban or outermost regions.

Regarding the clinical manifestations of PCM, the chronic form was the most prevalent and observed in $90.06 \%$ of the patients, a proportion that was not skewed

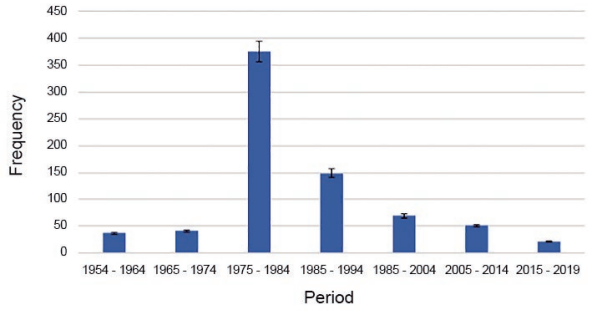

Fig. 1: temporal distribution of paracoccidioidomycosis (PCM) cases in Venezuela from 1954 to 2019.

by gender. On the other hand, the acute form only represented $9.93 \%$ of the reported cases (Table III). The most affected organs associated with chronic forms were lung $(100 \%)$, skin $(43.22 \%)$, followed by oral mucosa $(28.32 \%)$ and nose $(10.60 \%)$; other organs were affected in $8.32 \%$ cases (Table IV).

The main manifestations associated with the clinical forms of PCM were fever, observed in $72.7 \%$ of acute/ subacute cases and $27.3 \%$ of chronic cases; weight loss was also observed in $70 \%$ of all studied cases. Pulmonary infiltrates were observed in all patients with the chronic form. In addition, patients diagnosed with acute/subacute PCM had generalised lymphadenopathy $(95.6 \%)$, splenomegaly $(44.2 \%)$ and hepatomegaly (35.6\%). In PCM patients with the chronic form, the lesions were primarily located in the skin in $47.98 \%$ of the patients and oral mucosa involvement was observed in $31.44 \%$ of cases (Table IV).

The most frequent comorbidity was HIV/AIDS, found in 19 of the 745 patients $(2.55 \%)$. We observed four patients co-infected with histoplasmosis and four reported carcinomas; one patient had tuberculosis combined with a chronic multifocal form of PCM (Table III). The diagnosis was confirmed using three techniques: direct microscopic examination of various patient samples (obtained by biopsy, sputum and exudate aspiration), culture and double immunodiffusion (Table V). Conventional culture had $86.30 \%$ sensitivity $(95 \% \mathrm{CI}=84 \%$ - $88 \%$ ) and colonies were obtained in 14 to 60 days. DID had $88.22 \%(95 \% \mathrm{CI}=86 \%-91 \%)$ and the serum titration average of our cohort was between 1:16 and 1:64. Sensitivity of direct examination was $73.69 \%$ (95\% CI $=71 \%-77 \%$ ). Pearson's Chi-Square statistical analysis of diagnosis tools sensitivity did not show a significant difference among the three techniques.

\section{Molecular epidemiology of PCM in Venezuela}

In our study, we identified 17 Paracoccidioides clinical isolated strains from Venezuela. All genotyping methods are congruent and suggest strong geographical isolation of a particular species of Paracoccidioides in Venezuela. Sixteen out of seventeen strains of Paracoccidioides were identified as $P$. venezuelensis; a single strain was typed as $P$. americana (PS2).

\section{DISCUSSION}

PCM is a systemic mycosis restricted to Latin America with a wide range of clinical manifestations that can affect any susceptible host and is considered endemic in 


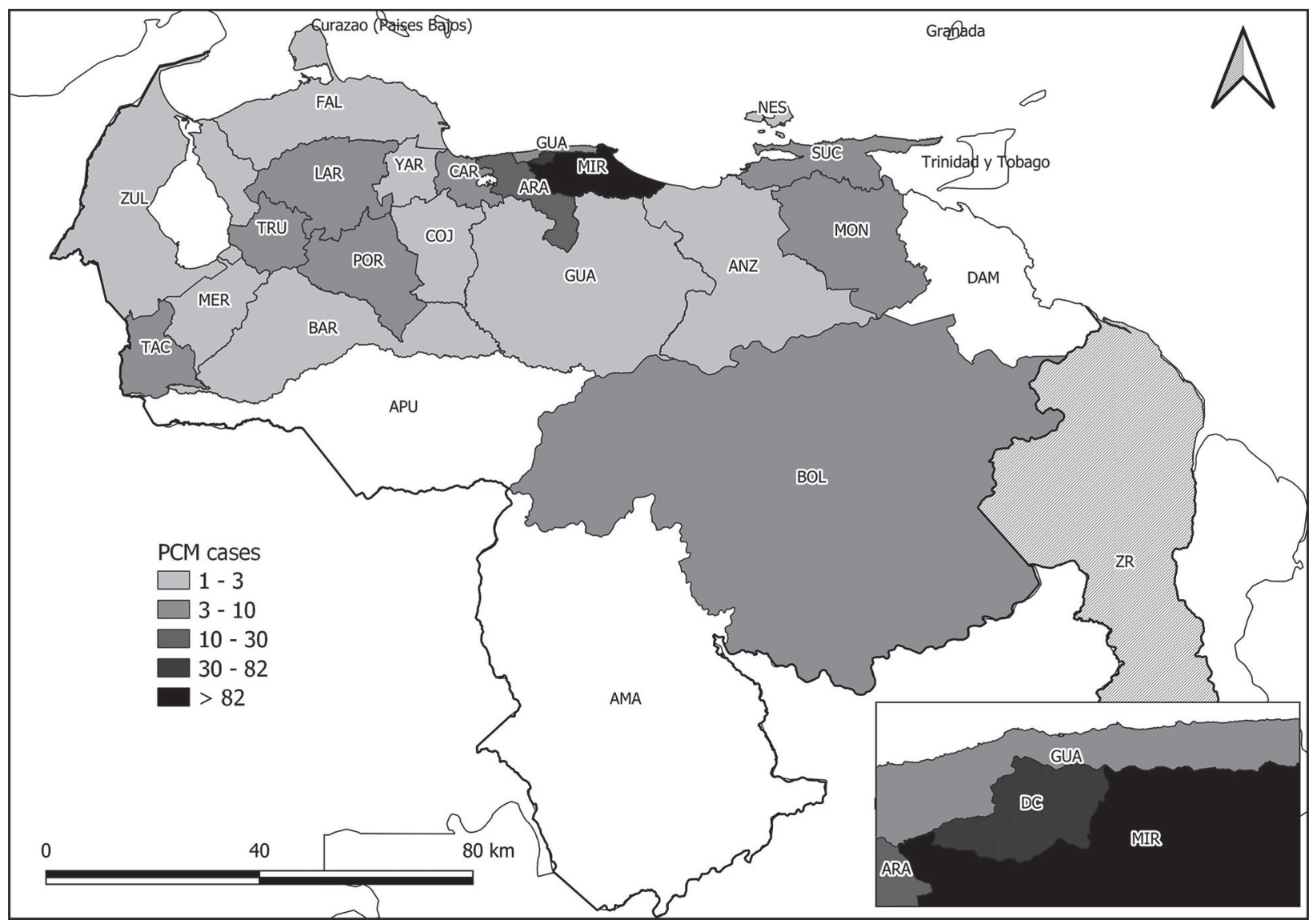

Fig. 2: geographic distribution of paracoccidioidomycosis (PCM) in Venezuela from 1954 to 2019. The states are abbreviated as follows: Amazonas (AMA), Anzoátegui (ANZ), Apure (APU), Aragua (ARA), Barinas (BAR), Bolívar (BOL), Carabobo (CAR), Cojedes (COJ), Delta Amacuro (DAM), Distrito Capital (DC), Falcón (FAL), Guárico (GUA), Lara (LAR), Mérida (MER), Miranda (MIR), Monagas (MON), Nueva Esparta (NES), Portuguesa (POR), Sucre (SUC), Táchira (TAC), Trujillo (TRU), La Guaira (GUA), Yaracuy (YAR), Zulia (ZUL). Base map obtained from the Simón Bolívar Geographical Institute of Venezuela (IGVSB). Data obtained from the Mycology Laboratory of the Autonomous Service Institute of Biomedicine "Dr Jacinto Convit".

Brazil, Venezuela, Colombia, Ecuador and Argentina. For example, Chile has no reports of autochthonous cases and this can be associated with a specific niche for fungal development. ${ }^{(24)}$ In this sense, the climate characteristic of Venezuela creates appropriate conditions for not only Paracoccidioides spp., but other dimorphic fungi that cause systemic mycoses such as Histoplasma spp. and Coccidioides posadasii. Thus, it is crucial to consider these agents as a differential diagnosis in granulomatous-like diseases. ${ }^{(25)}$ The reservarea suitable for the development of the Paracoccidioides spp. saprophytic phase in Venezuela, defined by Borelli, is characterised by tropical and subtropical areas surrounded by the Andes, San Luis mountains and the Macizo Guayanes, with a temperature range of $10^{\circ} \mathrm{C}$ to $28^{\circ} \mathrm{C}, 500$ to $2500 \mathrm{~mm} /$ per year pluviosity, an altitude ranging from 47 to 1,300 meters, acidic soil $\mathrm{pH}$ and abundant waterways. ${ }^{(26,27,28)}$

Our study depicted the epidemiology of PCM in Venezuela with 745 cases out of 31,081 medical charges in 65 years, all of them diagnosed in the Distrito Capital area. The clinical cases of PCM herein described and the recent reports of this disease allow us to confirm that Venezuela is the third most affected country with PCM in Latin America. However, it is estimated a significant underreporting throughout Latin America, and the number of PCM cases described in Colombia and Argentina, countries of high PCM incidence, could be also underestimated. ${ }^{(29)}$

Time-lapse distribution showed a higher prevalence between 1975 and 1984 with $52.01 \%$ of PCM diagnosed cases. After 1984 the patients' flow to the capital region decreased, which can be attributed to the deployment of well-trained personnel and the establishment of PCM workgroups around the country to achieve diagnosis outside the metropolitan area. In more recent times, roughly from 2005 onwards, the emigration of skilled professionals has meant that the scarce personnel left is mainly located in the Distrito Capital. The remaining working groups are liaising to improve the diagnosis and collect accurate data of PCM and other mycoses in Venezuela.

Regarding the geographic distribution, $75.03 \%$ of our cases were from Miranda State, a highly endemic region for PCM, followed by Distrito Capital with $12.61 \%$ and Aragua with $3.08 \%$. It is well-known that the north portion of the country has accounted for the highest number of cases; however, the epidemiological trends are evolv- 
TABLE III

Clinical forms of paracoccidioidomycosis (PCM) in Venezuela and its correlation with comorbidities and patient gender from 1954 to 2019

\begin{tabular}{|c|c|c|c|c|c|c|c|}
\hline & \multicolumn{2}{|c|}{ Female } & \multicolumn{2}{|c|}{ Male } & \multicolumn{2}{|c|}{ Total } & \multirow[b]{2}{*}{ p-value ${ }^{b}$} \\
\hline & $\mathrm{N}=144$ & $\%^{a}$ & $\mathrm{~N}=601$ & $\%^{a}$ & $\mathrm{~N}=745$ & $\%^{a}$ & \\
\hline \multicolumn{8}{|l|}{ Clinical forms } \\
\hline Acute/sub-acute & 7 & 4.86 & 67 & 11.14 & 74 & 9.93 & 0.008 \\
\hline Chronic & 137 & 95.13 & 534 & 88.85 & 671 & 90.06 & 0.008 \\
\hline \multicolumn{8}{|l|}{ Comorbidity } \\
\hline Carcinomas & 0 & 0 & 4 & 0.66 & 4 & 0.53 & 0.478 \\
\hline HIV/AIDS & 3 & 2.08 & 16 & 2.66 & 19 & 2.55 & 0.913 \\
\hline Histoplasmosis & 0 & 0 & 4 & 0.66 & 4 & 0.53 & 0.478 \\
\hline Tuberculosis & 0 & 0 & 1 & 0.16 & 1 & 0.13 & 1.000 \\
\hline
\end{tabular}

$a$ : proportion value based on calculations through contingency tables; $b$ : $\mathrm{p}$-value in a two-sample $\mathrm{z}$ test for the difference of proportions.

TABLE IV

Clinical forms of paracoccidioidomycosis (PCM) in Venezuela and affected organs

\begin{tabular}{|c|c|c|c|c|c|c|c|}
\hline \multirow[b]{2}{*}{ Affected organ } & \multicolumn{2}{|c|}{ Acute/sub-acute } & \multicolumn{2}{|c|}{ Chronic } & \multicolumn{2}{|c|}{ Total } & \multirow[b]{2}{*}{$\mathrm{p}$-value ${ }^{b}$} \\
\hline & $\mathrm{N}=74$ & $\%^{a}$ & $\mathrm{~N}=671$ & $\%{ }^{a}$ & $\mathrm{~N}=745$ & $\%^{a}$ & \\
\hline Oral mucosa & 0 & 0 & 211 & 31.44 & 211 & 28.32 & $<0,0001$ \\
\hline Nose & 0 & 0 & 79 & 11.77 & 79 & 10.60 & $<0,0001$ \\
\hline Lymph nodes & 61 & 82.43 & 2 & 0.29 & 63 & 8.45 & $<0,0001$ \\
\hline Eyes & 1 & 1.35 & 7 & 1.04 & 8 & 1.07 & 1,000 \\
\hline Skin & 0 & 0 & 322 & 43.22 & 322 & 43.22 & $<0,0001$ \\
\hline Lung & 74 & 0 & 671 & 100 & 745 & 100 & $<0,0001$ \\
\hline Other organs* & 12 & 16.22 & 50 & 7.45 & 62 & 8.32 & 0,069 \\
\hline
\end{tabular}

$a$ : proportion value based on calculations through contingency tables; $b$ : $\mathrm{p}$-value in a two-sample $\mathrm{z}$ test for the difference of proportions; *: skin, larynx, and central nervous system.

TABLE V

Laboratory diagnosis of paracoccidioidomycosis (PCM) from 1954 to 2019 in Venezuela

\begin{tabular}{lccccc}
\hline Test & Negative & $\%$ & Positive & $\%$ & Total \\
\hline Direct examination & 196 & 26.30 & 549 & 73.69 & 745 \\
\hline Conventional culture & 102 & 13.69 & 643 & 86.30 & 745 \\
\hline Serology (IDD) & 67 & 11.07 & 502 & 88.22 & 569 \\
\hline
\end{tabular}

*: IDD was available from 1975.

ing so that the entire country can be considered endemic to PCM. It has been reported that PCM is endemic in Carabobo, Lara, Monagas and Aragua states; throughout the years, our workgroup in Distrito Capital has received patients from all over the country. Those observations allow us to hypothesise a high rate of miss-notification and sub-diagnosis across Venezuela, such as in the Delta Amacuro, Apure and Amazonas states. ${ }^{(30)}$
About demographic features, $80.67 \%$ of patients were males in a 4:1 ratio in comparison with female affection, as previously reported in other endemic countries such as Brazil (93.4\%), Colombia (80\%) and Argentina $(70 \%)$; in Brazil, there is a wide range of male-female ratio reported from $3: 1$ to $10: 1$ according to the population studied. ${ }^{(31,32,33,34)}$ In Venezuela, highly endemic areas such as Miranda can have a higher male-female proportion. Another study cohort with Venezuelan patients reports a similar male-female ratio $6,5: 1$ in the studied population. (28) Although PCM is more prevalent in males, females are susceptible to acquiring or developing the infection previously to menarche or post-menopause due to the interaction between estrogens and Paracoccidioides spp. ${ }^{(35)}$

This mycosis has been associated with farming, a traditionally male activity; nevertheless, data of PCM cases in women is increasing. In a recent 2020 study, a group of Brazilian women between 40 and 50 years was affected and the social history of patients revealed to be housewives and rural workers with systemic changes at 
the time of PCM diagnosis, namely: pregnancy, HIV infection and/or depression. All these factors are related to hormonal impairment, contact with a massive inoculum size as observed in traditionally male activities such as farming, or immunological alterations that affect cellular response in the female hosts. ${ }^{(36)}$ Of note, our series showed 21 cases of chronic form in adult women younger than 48 and one more case which had HIV coinfection; this indicates that the distribution of PCM clinical cases is in fact much more skewed than evident by a plain male: female ratio, as age stratified ratios on Table IV highlight. We suggest that female cases of PCM in reproductive age should be treated with special care, as it cannot be excluded that factors related to the fungus itself may influence the occurrence of non-climacteric, adult female cases.

In our study, $33.02 \%$ of the patients diagnosed were in the 41-51 age range; there is copious literature that reports PCM infection in patients from 2 to 102 years old, with most cases being reported in patients over $30 .{ }^{(14,37)}$ Immunosenescence plays a role in the development of PCM in elderly patients, along with the interaction of hormone receptors previously discussed. ${ }^{(35)}$ Our data showed that the more susceptible occupations to acquire and develop PCM were farmers (32.48\%) and others with substantial exposure risk (manual workers, builders; $32.34 \%$ ), which might be related to a high inoculum of conidia. In both cases, conidia are inhaled by the direct contact with soil and dust originated from their activities. ${ }^{(38,39)}$ In the last decade, a substantial fraction of the low-income Venezuelan population has turned to agriculture as a response to a profound economic shortage: in search of a profitable side job, people go into farming of sugarcane, coffee, rice, cotton, corn and other crops. Additionally, migration of rural population into urban areas, job shifting and the fact that this mycosis is diagnosed many years after primo-infection have generated a scenario where the disease does not correlate strongly with the patients' occupation and the location of cases in medical registers of the evaluated patients. ${ }^{(28)}$

Regarding clinical forms of PCM, our study showed that patients between 30 to 60 years old developed chronic disseminated PCM with $90.06 \%$ of the clinical manifestation. Only $9.93 \%$ of cases were classified as acute/juvenile forms. Chronic PCM presentation is the most prevalent clinical form of the disease and is widely reported in adult and elderly patients in other countries in South America; ${ }^{(14)}$ it can be unifocal or multifocal according to the number of organs affected in hosts. Chronic PCM can lead to a wide range of nonspecific systemic symptoms and mimic other granulomatous diseases, and diagnosis is challenging. ${ }^{(14,40)} \mathrm{Re}-$ garding the organs affected in the patient metadata, the skin was the most reported $(43.22 \%)$, followed by oral mucosa (28.32\%); $8.32 \%$ of patients showed disease in other sites, including nose, larynx, and central nervous system. It is well documented that the chronic form is the most prevalent among male patients and usually affects oral mucosa, upper and lower respiratory tracts. Therefore, skin and oral manifestations, along with high suspicion due to epidemiological information, must be a clue for physicians to suspect PCM infections. ${ }^{(14,31,41)}$
As for comorbidities, 19 (2.55\%) of our patients had HIV/AIDS with PCM diagnosed after 1989, which concurs with the emergence of the AIDS pandemic; literature refers that $5 \%$ of the patients with HIV/AIDS can develop PCM. However, the correlation between HIV/ AIDS and PCM is slowly decreasing due to the early initiation of antiretroviral treatment in these patients. ${ }^{(42)}$ In addition, four patients had concurrent neoplasms, four had histoplasmosis, and only one had TB coinfection. Previously, authors have established the association between TB and PCM, ranging from $15 \%$ to $20 \%$ of incidence. ${ }^{(43)}$ Other reports from Venezuela had shown a higher concurrence of PCM and histoplasmosis, representing over $28 \%$ of the studied cases. ${ }^{(4)}$ Authors such as Shikanai-Yasuda previously report carcinoma concurrence in $0.16 \%$ to $14.1 \%$ of patients during PCM infection or after therapeutic management of PCM. In any case, a reliable and interdisciplinary study of clinical manifestations is mandatory to rapidly discard any malignancy associated with PCM lesions. ${ }^{(45)}$

About mycological diagnosis, three techniques were assessed to accomplish the diagnosis: DID with $88.22 \%$, followed by conventional culture with $86.30 \%$ and direct examination with $73.69 \%$ of sensitivity, respectively. Pearson's Chi-Square Statistical analysis of diagnosis tools sensitivity did not show significant difference among the three techniques, which leads us to state that any of the tools can satisfactorily accomplish the diagnosis by well-trained personnel and that having more than one test available can improve the quality and increase the speed of diagnosis. It must be noted, though, that authors such as Sylvestre et al. in 2014 quoted a high sensitivity of serology up to $80 \%$ after antifungal treatment ${ }^{(20)}$ so past disease may be a confounding factor when trying to find the cause of a mucocutaneous lesion and PCM is suspected.

Previous studies have reported that culture in SDA is a gold standard in the diagnosis algorithm of PCM; however, Paracoccidioides spp. is a slow-growing fungus, which affects the sensitivity of conventional culture methods. ${ }^{(46)}$ In contrast, other authors such as Hahn et al. ${ }^{(47)}$ report a high sensitivity in mycological culture (97\%) and direct examination $(88.2 \%)$ in $P$. lutzii. It is worth pointing out that in our case series, from 1954 through 1974, direct examination and mycological culture were the only available methods to PCM diagnosis, and DID was included as a complementary diagnostic tool after 1975.

In our study, we included 745 isolated strains from clinical samples in a 65 -years period; most of the previously collected strains were stored according to Castellani's method. After a variable period (1 to 65 years), only $56(8.7 \%)$ strains were successfully recovered, and 17/56 were qualified as appropriate for the molecular study. (11) Paracoccidioides spp. culture and storage are still a challenge; conventional storage methods are Castellani's technique or mineral oil conservation. Previous authors report a $26 \%$ recovery rate of the collected strains onto fresh culture media, with a limit of ten years of storage. ${ }^{(48)}$

Our study documents the epidemiological history of PCM in Venezuela and is the third-largest case series after studies from Colombia and Brazil. ${ }^{(14,29,38)}$ Molecular 
epidemiological studies carried out so far in Venezuela suggest that $P$. venezuelensis (or PS4) is the main etiological agent of PCM, which our study seems to confirm. Genomic analysis indicates that $P$. venezuelensis represents a unique genotype in the Paracoccidioides genus and shares a common ancestor with $P$. restrepiensis, which is endemic to Colombia. ${ }^{(1)}$

This retrospective study allowed us to establish an epidemiological footprint of PCM in Venezuela during a 65 -year period, confirming the significant endemicity of this mycosis in our country. Comprehension and knowledge of clinical, epidemiological and genomic data can help us implement an adequate disease follow-up. It is important to highlight that this mycosis is not considered a mandatory notification disease despite being linked to a significant rate of morbimortality in underdeveloped countries such as Venezuela.

\section{ACKNOWLEDGEMENTS}

To Dr Sofía Mata-Essayag, who provided excellent technical support in the preparation of this manuscript.

\section{AUTHORS' CONTRIBUTION}

PA, MT and HCP - Conceptualisation; PA and MT - methodology; PA and MT - formal analysis; PA and GG - investigation; EC and GS - resources; GS - data curation; PA and RM - writing - original draft preparation; PA, MT, HCP and RM - writing - review \& editing; EC - visualisation; PA - supervision. The authors declare no conflict of interest.

\section{REFERENCES}

1. Canteros C. Paracoccidioidomycosis: chronicle of a neglected disease. Medicina (B Aires). 2018; 78(3): 180-4.

2. De Macedo PM, Almeida-Paes R, Freitas DFS, Varon AG, Paixao AG, Romão AR, et al. Acute juvenile Paracoccidioidomycosis: a 9 -year cohort study in the endemic area of Rio de Janeiro, Brazil. PLoS Negl Trop Dis. 2017; 11(3): e0005500.

3. Souza RAL, Bonan PRF, Pinto MBR, Prado JD, de Castro JFL, Carvalho EJA, et al. Oral paracoccidioidomycosis in a non-endemic region from Brazil: a short case series. J Clin Exp Dent. 2019; 11(10): e865-70.

4. Theodoro RC, Teixeira MM, Felipe MSS, Paduan KS, Martins Ribolla P, San-Blas G, et al. Genus Paracoccidioides: species recognition and biogeographic aspects. PLoS One. 2012; 7(5): e37694.

5. Restrepo A, Cano LE, Gonzalez A. The power of the small: the example of Paracoccidioides brasiliensis conidia. Rev Inst Med Trop São Paulo. 2015; 57(Suppl. 19): 5-10.

6. Gonzalez A, Hernandez O. New insights into a complex fungal pathogen: the case of Paracoccidioides spp. Yeast. 2016; 33(4): $113-28$.

7. Teixeira MM, Theodoro RC, Nino-Vega G, Bagagli E, Felipe MS. Paracoccidiodes species complex: ecology, phylogeny, sexual reproduction and virulence. PLoS Pathog. 2014; 10(10): e1004397.

8. Teixeira MM, Theodoro RC, de Carvalho MJA, Fernandes L, Paes $\mathrm{CH}$, Hahn R, et al. Phylogenetic analysis reveals a high level of speciation in the Paracoccidioides genus. Mol Phylogenet Evol. 2009; 52(2): 273-83.

9. Queiroz-Telles F, Pietrobom PMP, Rosa Jr M, Baptista RM, Peçanha PM. New insights on pulmonary paracoccidioidomycosis. Semin Respir Crit Care Med. 2020; 41(1): 53-68.
10. Turissini DA, Gomez OM, Teixeira MM, McEwen JG, Matute DR. Species boundaries in the human pathogen Paracoccidioides. Fungal Genet Biol. 2017; 106: 9-25.

11. Teixeira MM, Cattana ME, Matute DR, Muñoz JF, Arechavala A, Isbell K, et al. Genomic diversity of the human pathogen Paracoccidioides across the South American continent. Fungal Genet Biol. 2020; 140: 103395.

12. Shikanai-Yasuda M, Queiroz Telles F, Mendes RP, Colombo AL, Moretti L. Consenso em paracoccidioidomicose. Rev Soc Bras Med Trop. 2006; 39(3): 297-310.

13. Shikanai-Yasuda M, Mendes R, Colombo AL, de Queiroz-Telles F, Kono ASG, Paniago AM, et al. Brazilian guidelines for the clinical management of paracoccidioidomycosis. Rev Soc Bras Med Trop. 2017; 50(5): 715-40.

14. Martinez R. New trends in paracoccidioidomycosis epidemiology. J Fungi (Basel). 2017; 3(1): 1.

15. O’Daly JA. Las blastomicosis en Venezuela. (Primera comunicación). Boletín. Hospital Vargas Distrito Federal (Vzla). 1937; 36: $127-56$.

16. Guerra D. El granuloma a Paracoccidioides. Su importancia en patología pulmonar. Rev San Asist Soc Venezuela. 1948; 4: 921-7.

17. De Albornoz MB. Isolation of Paracoccidioides brasiliensis from rural soil in Venezuela. Sabouraudia. 1971; 9: 248-53.

18. Cermeño JR, Hernández I, Cermeño J, Godoy G, Cermeño JJ, Orellán Y, et al. Epidemiological survey of histoplasmine and paracoccidioidine skin reactivity in an agricultural area in Bolívar state, Venezuela. Eur J Epidemiol. 2004; 19(2): 189-93.

19. Hartung de Capriles C, Mata-Essayag S, Middelveen M. Preservation of fungi in water (Castellani): 20 years. Mycopathologia. 1989; 106(2): 73-9.

20. Sylvestre TF, Silva LRF, Cavalcante RS, Moris DV, Venturini J, Vicentini AP, et al. Prevalence and serological diagnosis of relapse in paracoccidioidomycosis patients. PLoS Negl Trop Dis. 2014; 8(5): e2834.

21. Niño-Vega G, Calcagno AM, San-Blas G, San-Blas F, Gooday GW, Gow NA. RFLP analysis reveals marked geographical isolation between strains of Paracoccidioides brasiliensis. Med Mycol. 2000; 38(6):437-41.

22. Campbell I. Chi-squared and Fisher-Irwin tests of two-by-two tables with small sample recommendations. Stat Med. 2007; 26(19): 3661-75.

23. Bravo-Grau S, Cruz JP. Diagnostic accuracy studies: tools for its interpretation. Rev Chil Radiol. 2015; 21: 158-64.

24. Mendes RP, Cavalcante RS, Marques SA, Marques MEA, Venturini J, Sylvestre T, et al. Paracoccidioidomycosis: current perspectives from Brazil. Open Microbiol J. 2017; 31(11): 224-82.

25. Cermeño J, Cermeño J, Godoy G, Hernández I, Orellán Y, Blanco $\mathrm{Y}$, et al. Epidemiological study of paracoccidioidomycosis and histoplasmosis in a suburb of San Félix city, Bolívar State, Venezuela. Invest Clin. 2009; 50: 213-20.

26. Borelli D. Concepto de reservarea. La reducida reservarea de paracoccidioidomicosis. Dermat Venezol. 1963-1964; 3(1-2): 130-2.

27. Albornoz MB, Albornoz R. Estudio de la sensibilidad específica en residentes de un área endémica a la paracoccidioidomicosis en Venezuela. Mycopathol Mycol. 1971; 45: 65-75.

28. Dawaher J, Colella M, Roselló A, Pérez C, Olaizola C, Newman W, et al. Paracoccidioidomicosis: clínica, epidemiología y tratamiento. Kasmera. 2012; 40: 160-71. 
29. Calle D, Rosero DS, Orozco LC, Camargo D, Castañeda E, Restrepo A. Paracoccidioidomycosis in Colombia: an ecological study. Epidemiol Infect. 126(2): 309-15.

30. Martínez D, Hernández R, Alvarado P, Mendoza M. Las micosis en Venezuela: casuística de los grupos de trabajo en micología 1984 - 2010. Rev Iberoam Micol. 2013; 30(1): 39-46.

31. Arruda JAA, Schuch LF, Abreu LG, Silva LVO, Mosconi C, Monteiro JLGC, et al. A multicentre study of oral paracoccidioidomycosis: analysis of 320 cases and literature review. Oral Dis. 2018; 24(8): 1492-502.

32. Brummer E, Castaneda E, Restrepo A. Paracoccidioidomycosis: an update. Clin Microbiol Rev. 1993; 6(2): 89-117.

33. Tracogna MF, Lugo SF, Vázquez MG, Fernández MS, Andriani $\mathrm{ME}$, Presti S, et al. Clinical and epidemiological characteristics of patients with paracoccidioidomycosis diagnosed in a hospital of Resistencia, Chaco. Rev Argent Microbiol. 2018; 51(2): 144-7.

34. Trindade AH, Meira HC, Pereira IF, Lacerda JCT, Mesquita RA, Santos VR. Oral paracoccidioidomycosis: retrospective analysis of 55 Brazilian patients. Mycoses. 2017; 60(8): 521-5.

35. Restrepo A, Salazar ME, Cano E, Stover P, Feldman D, Stevens D. Estrogens inhibit mycelium-to-yeast transformation in the fungus Paracoccidioides brasiliensis: implications for resistance of females to paracoccidioidomycosis. Infect Immun. 1984; 46(2): 346-53.

36. Costa MC, Carvalho MM, Sperandio FF, Ribeiro Jr NV, Hanemann JAC, Pigossi SC, et al. Oral paracoccidioidomycosis affecting women: a systematic review. Mycoses. 2021; 64(2): 108-22.

37. Martinez R. Epidemiology of paracoccidioidomycosis. Rev Inst Med Trop São Paulo. 2015; 57(Suppl. 19): 11-20.

38. Bellíssimo-Rodrigues F, Machado AA, Martinez R. Paracoccidioidomycosis epidemiological features of a 1000 -cases series from a hyperendemic area on the Southeast of Brazil. Am J Trop Med Hyg. 2011; 85(3): 546-50.

39. Coimbra Jr CE, Wanke B, Santos RV, do Valle AC, Costa RL, Zancopé-Oliveira RM. Paracoccidioidin and histoplasmin sen- sitivity in Tupí-Mondé Amerindian populations from Brazilian Amazonia. Ann Trop Med Parasitol. 1994; 88(2): 197-207.

40. Peçanha PM, Batista Ferreira ME, Peçanha MAM, Schmidt EB, Araújo ML, Zanotti RL, et al. Paracoccidioidomycosis: epidemiological and clinical aspects in 546 cases studied in the State of Espírito Santo, Brazil. Am J Trop Med Hyg. 2017; 97(3): 836-44.

41. Merino-Alado R, Mata-Essayag S, Pineda J, Moronta G, BriceñoCaveda E, Mujica V, et al. Oral manifestations associated to paracoccidioidomycosis and histoplasmosis. Pesq Bras Odontoped Clin Integr. 2018; 18(1): e3846.

42. Morejón KM, Machado AA, Martinez R. Paracoccidioidomycosis in patients infected with and not infected with human immunodeficiency virus: a case-control study. Am J Trop Med Hyg. 2009; 80(3): 359-66.

43. Quagliato Jr R, Grangeia TAG, Massucio RAC, De Capitani EM, Rezende SM, Balthazar AB. Association between paracoccidioidomycosis and tuberculosis: reality and misdiagnosis. J Bras Pneumol. 2007; 33(3): 295-300.

44. Merino-Alado R, Pineda J, Rasquin JH, Landaeta ME, Mata-Essayag S. Granulomatous mastitis due to coinfection with Histoplasma sp. and Paracoccidioides sp.: a case report. Med Mycol Case Rep. 2020; 27: 52-4.

45. Shikanai-Yasuda MA, Conceição YMT, Kono A, Rivitti E, Campos AF, Campos SV. Neoplasia and paracoccidioidomycosis. Mycopathologia. 2008; 165(4-5): 303-12.

46. Marques S. Paracoccidioidomycosis. Clin Dermatol. 2012; 30(6): $610-5$.

47. Hahn RC, Rodrigues AM, Della Terra PP, Nery AF, HoffmannSantos HD, Góis HM, et al. Clinical and epidemiological features of paracoccidioidomycosis due to Paracoccidioides lutzii. PLoS Negl Trop Dis. 2019; 13(6): e0007437.

48. Da Silva AM, Borba CM, de Oliveira PC. Viability and morphological alterations of Paracoccidioides brasiliensis strains preserved under mineral oil for long periods of time. Mycoses. 1994; 37(5-6): 165-9. 